\title{
Educação para a Saúde: discutindo uma prática pedagógica integral com jovens em situação de risco
}

\section{Health Education: discussing an integral pedagogical practice with young people at risk}

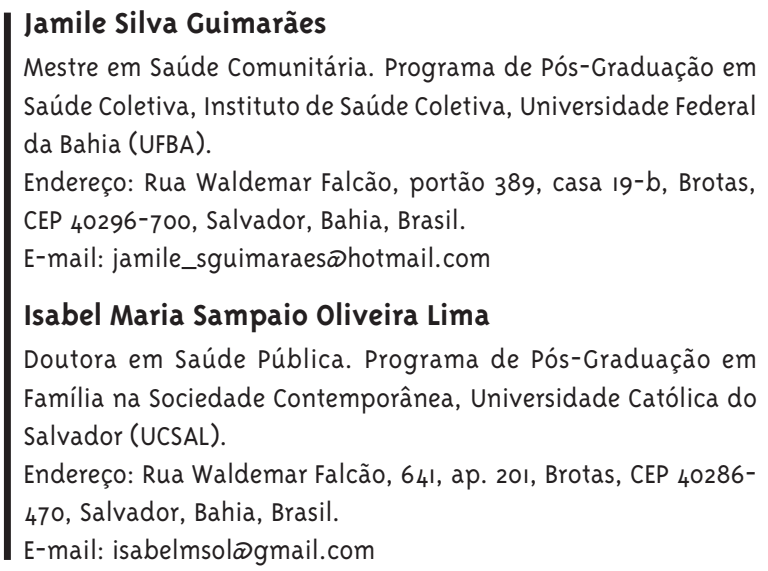

\section{Resumo}

Este artigo objetivou analisar os fundamentos teórico-metodológicos de uma prática educativa integral em saúde promovida por uma ONG junto a jovens em situação de risco pessoal e social. Foram realizadas entrevistas em profundidade com seis participantes, observação sistemática das atividades educativas e pesquisa documental de textos, reportagens e vídeos no blog institucional. Articulando métodos diversos, esta ação educativa promove o diálogo e uma dinâmica de problematização, trabalhando em grupos cooperativos e fortalecendo relações horizontais entre os jovens e os educadores. Os resultados apontam para a formação de uma postura reflexiva que permitiu aos jovens ressignificar tabus e mitos sobre questões de saúde e compreender melhor a si mesmos, constituindo-se como sujeito. A análise crítica da informação mostra-se essencial para que se estabeleça uma relação entre o conhecimento e seu valor para a vida, e, por conseguinte, a saúde. 0 sentido construído é parâmetro de escolhas e motor de ações de autocuidado. Ao criar condições para que o jovem reflita e explore conceitos e procedimentos sociais e de saúde, esta prática educativa lhe oportuniza construir uma visão sobre a saúde e o significado de ser saudável. Conclui-se que o desenvolvimento da capacidade de análise, discernimento e decisão recursa ao jovem para organizar e conduzir sua vida pessoal e coletiva, de forma mais crítica, autônoma e participativa.

Palavras-chave: Juventude; Educação em Saúde; Metodologia de ensino-aprendizagem; Desenvolvimento humano. 


\section{Abstract}

This article aims at analyzing the theoretical and methodological fundamentals of an integral educational experience of practice in health promoted by an NGO with youngsters at personal and social risk. In-depth interviews were conducted with six participants, as well as systematic observation in educational activities and research in documents, reports and videos on the institutional blog. Articulating different methods, this educational activity promotes dialogue and a dynamics of questioning, working in cooperative groups and strengthening horizontal relationships between youngsters and educators. Results indicate that health education induced the formation of a reflexive stance that allowed young people to reframe taboos and myths about health issues, and a better understanding of themselves. Information's critical analysis seems to be essential to establish a relationship between knowledge and its value for life and for health. The meaning built through this analysis is a parameter for choices and engines actions of self-care. By creating conditions for the young to reflect and explore concepts and procedures in society and regarding health, the methodology adopted nurtures the development of meanings for health and being healthy. It is concluded that analytical capacity, discernment and decision support helps the youngsters to organize and conduct their personal and collective life, in a more critical, autonomous and participatory way.

Keywords: Youth; Health Education; Methodology for teaching and learning; Human Development.

\section{Introdução}

A Educação em Saúde constitui-se na combinação de experiências de aprendizagem delineadas para desencadear ações conducentes à saúde (Candeias, 1997). Enquanto expressão da vida e do conhecimento, os saberes e as práticas convertem-se em recursos para a adoção de novos hábitos e condutas de saúde. Mobilizar as pessoas a atuarem em prol da própria saúde requer intervenções educativas que promovam uma compreensão dos condicionantes da saúde, relacionando-os ao viver cotidiano.

Por meio de uma abordagem preventiva, a educação em saúde tradicional segue as postulações do behaviorismo e do individualismo, trabalhando com a ideia de que os modos de vida dos indivíduos são as principais causas da falta de saúde (Rodmell e Watt, 1986). Partindo da hipótese de que os problemas de saúde resultam da precária situação educacional da população em geral, esta prática pedagógica objetiva a aquisição de novos comportamentos e atitudes. Os comportamentos inadequados seriam passíveis de serem corrigidos pelos indivíduos, mediante informações científicas oferecidas por profissionais da saúde, como uma questão de escolha pessoal.

Desde a década de 1970, com a organização dos movimentos sociais e a interlocução com teorias das Ciências Humanas, o campo teórico da Educação em Saúde tem sido vigorosamente repensado em suas práticas autoritárias e normalizadoras. Propostas de Educação Popular em Saúde, inspiradas na pedagogia libertadora de Freire, visam romper com a verticalidade da relação educador-educando e a transitoriedade das ações, ao valorizar trocas interpessoais, o diálogo e a compreensão do saber popular (Vasconcelos, 2001).

A principal crítica ao modelo hegemônico refere-se a não consideração dos determinantes psicossociais e culturais nos comportamentos de saúde. Ao tomar os usuários como objeto das práticas educativas e carentes de conhecimento sobre saúde, perde-se de vista que os comportamentos são orientados por crenças, valores e representações sobre o processo saúde-doença.

Diversas pesquisas têm demonstrado que a informação é apropriada pelos indivíduos, que elaboram significados próprios do que lhes foi transmitido 
(Lima-Costa e col., 2002; Gazzinelli e col., 2005). Os aspectos subjetivos, igualmente, devem ser analisados através do papel das histórias de vida na construção da capacidade volitiva. A percepção pessoal, portanto, aparece como fator decisivo à mudança de comportamentos.

Na constatação da ineficácia do modelo de comunicação informacional, é estabelecido o distanciamento entre o discurso e a prática pedagógica na Educação em Saúde. Nas últimas décadas, mediante a contribuição das Ciências Sociais Contemporâneas e de estudos da Antropologia da Saúde, vários autores têm enfatizado a importância de se observar o sujeito em sua totalidade. A atenção aos processos intelectuais, afetivos e culturais tem constituído uma via para lograr maior efetividade em termos da mudança de conduta (Alves e Rabelo, 1998). Esta reorientação crescente das reflexões teóricas e metodológicas busca superar a visão biomédica e avançar na compreensão da complexidade que caracteriza o campo da Educação em Saúde.

O modelo emergente pode ser referido como modelo dialógico por ser o diálogo o seu instrumento essencial. Através do uso de estratégias participativas, reconhece-se o usuário como sujeito das práticas de saúde, enquanto premissa para o entendimento das necessidades subjetivas e das características culturais das pessoas (Ayres, 2001).

Em termos educacionais, este modelo visa à transformação de saberes da população mediante o desenvolvimento da compreensão acerca de sua situação de saúde (Smeke e Oliveira, 2001; Gazzinelli e col., 2005). Sua prática pedagógica, entretanto, permanece focalizada na responsabilidade pessoal do cuidado com a saúde. Sob a égide da emancipação, a ideia é capacitá-los para decidir sobre sua saúde, mediante a aquisição de habilidades e do aprendizado de formas "adequadas" de pensar e fazer (Ferraz e col., 2005). A prevalência da racionalidade biomédica nos serviços oficiais e na formação de recursos humanos condiciona as práticas educativas, ainda organizadas a partir de uma noção individualista de saúde representada como produto de decisões racionais quanto ao comportamento (Oliveira, 2005).

Na revisão de literatura que precedeu a elaboração deste artigo, foram identificados alguns fatores decorrentes do tensionamento próprio às estraté- gias utilizadas. Estes fatores podem ser elencados quanto ao tempo, à expressão do público-alvo, aos limites das propostas de Educação Popular, à emergência territorial e cultural dos temas e aos próprios recursos humanos. Examinando esses aspectos, tem-se a questão da temporalidade quando os projetos são de curto prazo e o trabalho focado no aquiagora. Esta restrição temporal impossibilita aos profissionais de saúde conhecer as representações e o processo de apropriação e definição cultural dos usuários. Perde-se, assim, a ocasião de fornecer-lhes instrumentos para a reflexão sobre suas atitudes e práticas. Quanto à espontânea reação do públicoalvo, este frequentemente não tem a oportunidade de expressar suas percepções sobre os problemas de saúde, suas prioridades e propostas de solução. Em relação às propostas de Educação Popular, observa-se a centralidade da produção de oficinas e círculos de cultura que, por sua curta duração, promovem apenas um estímulo temporário, limitando a assimilação e a manutenção dos novos hábitos. Apresentam um efeito similar aos das campanhas prescritivas "não fume" ou "use camisinha" que, tão logo interrompidas, a população rapidamente esquece a informação. Relativamente à produção vertical (em âmbito federal) de materiais de referências e a definição de diretrizes das políticas e programas de saúde, observa-se que estes inibem a participação protagonista dos usuários. Neste ponto, destaca-se a importância da territorialização de temas transversais, tais como violência, uso de drogas, desenvolvimento sustentável, nutrição, obesidade, dentre outros. Sobre a formação de recursos humanos em uma prática disciplinar, tem-se que é considerada condicionada por uma estrutura organizativa setorial que dificulta a articulação entre saúde, cultura e educação. Uma formação de caráter holístico passa, necessariamente, pelo desenvolvimento da capacidade de diálogo com o saber prático das pessoas e grupos, oferecendo elementos que possam fazer sentido em seu universo cultural e projetos de vida (Rice e Candeias, 1989; Gazzinelli e col., 2005; Oliveira, 2005; Beserra e col., 2006; Lopes e Malfitano, 2006).

Neste artigo, considera-se a educação em saúde como uma construção compartilhada de conhecimento que advém das experiências e práticas dos 
sujeitos envolvidos (Carvalho e col., 2001). Um ambiente intersubjetivo vem a ser aquele que fornece instrumentos culturais, sociais e afetivos para que os sujeitos empreendam a construção do seu ser e modifiquem as relações sociais que influenciam sua qualidade de vida. Configura-se justificado, portanto, indagar quais aspectos e elementos desencadeariam esse processo transformador do desenvolvimento humano integral.

Uma abordagem integral no processo educativo enseja a atenção à coconstrução entre a dimensão perceptual-vivencial e a práxis dos sujeitos (Goodman, 1997; Freire, 2006). A perspectiva pragmática e situacional é comtemplada quando o processo educativo assume-se como mediador da inserção social, adotando como fundo a vivência cotidiana e as relações com o mundo. Neste ponto, importa compreender a apropriação pessoal dos processos socioculturais, para adentrar no âmago da formação de vínculos com o coletivo e da própria individualidade (Vygotsky, 2007).

A despeito da tradição da objetividade nas práticas de saúde, considera-se necessário integrar tanto a subjetividade quanto a troca intersubjetiva como elementos constituintes da experiência humana. As emoções e sentimentos manifestam a afetividade que brota nas relações, e vis-à-vis, são fundamentais na elaboração dos significados que configuram a "estrutura da consciência”, conjuntamente com os processos cognitivos e volitivos (Vygotsky, 2008). Destarte, mesmo um contexto educativo se apoia na aprendizagem informal que emerge na intersubjetividade dos alunos. A vivência lúdica entre os pares constitui parte essencial da construção do conhecimento. Por meio da imaginação e da fantasia, as manifestações artísticas estabelecem uma forma de assimilação, reflexão e ressignificação do referencial social, histórico e cultural (Vygotsky, 2007).

Consoante a esta abordagem, o presente artigo objetiva analisar os fundamentos teórico-metodológicos de uma experiência de prática educativa de caráter integral voltada a jovens em situação de risco pessoal e social. Será apresentado como a articulação dos métodos pedagógicos da Educação problematizadora, da Aprendizagem cooperativa e da Educação entre pares plasma saberes, de modo a abranger as múltiplas dimensões do ser humano.

\section{Metodologia}

Trata-se de um estudo qualitativo sobre uma prática educativa integral desenvolvida por uma Organização Não Governamental (ONG), junto a jovens procedentes de comunidades periféricas da cidade do Salvador. Tendo a experiência da Educação em Saúde como eixo da discussão, buscou-se destacar os elementos característicos da prática pedagógica desenvolvida, articulando-os analiticamente com os fundamentos metodológicos relacionados à Educação problematizadora, à Aprendizagem cooperativa e à Educação entre pares.

Esses modelos apresentam pontos de convergência como o diálogo, a participação ativa dos educandos e a promoção de relações mais horizontais no processo educativo, todavia, suas estruturas organizativas são delineadas de forma distinta. Para efeito desta pesquisa, importa como a articulação de métodos possibilita conduzir um processo educativo de alcance pluridimensional.

O estudo foi realizado no Centro de Referência Integral de Adolescentes (CRIA) que, por meio da arte-educação, visa à formação para a cidadania e à atuação comunitária de adolescentes e jovens em situação de risco pessoal e social. Atualmente a organização trabalha com 69 adolescentes e jovens entre 15 e 29 anos, nos níveis de ensino médio e universitário, sendo 36 do sexo masculino e 33 do sexo feminino, com um período médio de 2 a 4 anos de participação nos quatro grupos de teatro e no grupo de poesia.

Fundada em 1994, esta ONG baiana desenvolveu uma metodologia de arte-educação, cuja práxis estrutura-se no Espaço de Linguagem e Expressão (ELE), onde as peças são criadas em parceria com os jovens, desde o planejamento das atividades e a concepção do projeto. Esse processo educativo constitui uma "autoavaliação individual e em grupo, que se traduz numa forma estética capaz de provocar consciência sobre a importância da pessoa e da coletividade nos processos de transformação" (CRIA, 2011). No rol das atribuições do CRIA está a discussão prática e teórico-conceitual das vivências da juventude e dos problemas enfrentados na família, escola e comunidade.

Baseando-se no Programa de Educação para a 
Cidadania do CRIA, elaborado em dinâmico processo de discussão, anualmente é oferecido um currículo focado nos eixos temáticos: Educação, Saúde e Cultura. A produção dos textos dos espetáculos é precedida por leitura de textos, pesquisas, debates com estudiosos e pesquisadores de universidades locais e elaboração de artigos sobre temas como questões étnico-raciais, cidadania, sexualidade na adolescência, gênero, direitos humanos, enfrentamento da violência sexual e doméstica, saúde sexual e reprodutiva, prevenção do HIV/AIDS, uso de drogas lícitas e ilícitas e discriminação social.

A ação educativa estende-se à participação dos jovens na gestão institucional e à atuação como multiplicadores, percorrendo os vários níveis de formação nomeados como monitor I e II, assistente e orientador. É igualmente estimulada a participação política, através da organização de eventos tanto para discutir políticas públicas para juventude quanto para tratar da inserção dos jovens em espaços de controle social.

Foram entrevistados seis jovens na faixa etária entre 24 e 29 anos, selecionados segundo os seguintes critérios de inclusão: (1) maior tempo de permanência - relaciona-se ao maior contato com os mecanismos pedagógicos de formação educativa; (2) diferenças na trajetória institucional - a diversidade de atividades oferecidas cria distinção interna entre os integrantes, assim, nem todos vivenciam as mesmas experiências ou gozam das mesmas oportunidades. Os níveis diferenciados de envolvimento com a organização e o que ela oferece, são importantes para verificar o papel educativo da ONG para além da formação em Artes, e (3) divisão equitativa por gênero.

Para melhor assimilar a perspectiva organizacional da ONG, decidiu-se, igualmente, entrevistar a coordenadora da área de Saúde, objetivando apreender os aspectos do contexto institucional e os processos e dinâmicas que envolvem e compõem as diversas atividades e relações estabelecidas no ambiente.

O projeto de pesquisa foi aprovado pelo Comitê de Ética em Pesquisa do Instituto de Saúde Coletiva da Universidade Federal da Bahia (ISC/UFBA), sob o protocolo de no 038/og. Todos os participantes concordaram com os objetivos e a metodologia da pesquisa, assinando o Termo de Consentimento Livre e Esclarecido. Para preservar o sigilo quanto à identificação dos informantes, optou-se pela utilização de nomes fictícios.

Para a obtenção dos dados, foram utilizados os seguintes instrumentos: (a) observação participante - no período de outubro de 2010 a janeiro de 2011 - para identificar os elementos estruturantes dos processos e dinâmicas de relações, aprendizagens e atividades que compõem o processo educativo; (b) entrevistas em profundidade objetivando compreender as percepções e os significados atribuídos pelos jovens educandos, e (c) pesquisa documental de materiais impressos produzidos pela ONG e de textos, reportagens e vídeos no blog institucional www.criando.org.br.

Para o tratamento dos dados, inicialmente foram construídas categorias de análise para descrever os aspectos culturais e os objetivos da prática pedagógica da organização (Minayo, 1996). Essas categorias reportavam-se às metodologias de aprendizagem supracitadas, organizadas em subcategorias que definiam seus conceitos e elementos característicos.

Com o fito de compreender as percepções e experiências dos educandos acerca do processo educativo, optou-se por um procedimento de análise de discurso. Foi adotada a perspectiva teórica proposta por Fiorin (2005), que concebe o discurso como uma rede de relações na qual o indivíduo está inserido. Para este autor, a análise do discurso revela-se um meio para a compreensão da visão de mundo dos indivíduos - entendida como o conteúdo de sua ação - e do contexto em que é produzido. Por meio do e no discurso pode-se apreender as dimensões sociais, culturais e simbólicas que nele se expressam e que explicam a forma pela qual os membros de sua comunidade discursiva se relacionam, comportam-se e agem.

\section{Resultados e Discussão}

\section{Educação problematizadora: lastro estruturante para a construção do conhecimento}

A educação problematizadora atua como eixo estruturante da relação institucional com os participantes. O caráter reflexivo desse método implica no aprofundamento constante da discussão sobre a realidade, para que os jovens construam sua con- 
cepção da vida social, compreendendo o seu lugar no mundo. Esse ato de imersão na consciência resulta em uma inserção crítica nesta realidade (Freire, 2005).

Observou-se que a reflexão originada nas experiências pessoais torna-se um contato analítico com a própria vida. Fundamenta-se na provocação de questionamentos dos jovens pelos educadores, retirando-os da zona de conforto característica da passividade, da alienação da certeza absoluta, dos mitos e tabus, muitos dos quais relacionados à sexualidade e à condição juvenil, tal como relataram os entrevistados.

Na condição de sujeito do processo educativo, o jovem sente-se desafiado a buscar respostas às emergentes inquietações, ampliando sua consciência crítica e transformadora. Segundo Benedito, "pensar sobre as coisas que nos afetam, é o ponto de partida para uma nova forma de agir". De fato, as falas dos jovens informantes expressam uma associação entre conscientização e constituição como sujeito, constantemente referida como seu "entendimento enquanto ser humano". Esta tradução do entendimento de si, enquanto jovem e cidadão, corrobora a ideia da educação como um processo de humanização em que o diálogo constitui uma base existencialista (Freire, 2005).

Na produção do conhecimento, conforma-se uma dinâmica ontológica que repercute na ressignificação do ser, tal como explica Sofia: "Através dessa participação você se constrói como indivíduo, isso te aponta milhares de oportunidades, de entender melhor as suas relações, o seu estar no mundo, o que você acredita, e constrói, fortalece suas ideologias”.

A adoção de uma perspectiva de aprendizagem pela ONG converte o educador em mediador do debate em torno de questões pertinentes aos temas em estudo. Problematizando conceitos e conteúdos para instigar a capacidade autoral e investigadora dos jovens.

Esta proposta de trabalho adquire especial interesse para o campo da Educação em Saúde uma vez que privilegia questões advindas dos interesses e necessidades dos jovens, que elaboram em grupos uma concepção ou uma proposta criativa para o problema (Magdalena e Costa, 2003). Nesse processo desenvolve-se uma cultura de autodidatismo, com a valorização do labor da pesquisa e da autoria de pensamento, que, nas narrativas dos jovens, aparece relacionado ao desenvolvimento de suas potencialidades e compreensão dos vários prismas que integram as questões de saúde e seus determinantes sociais.

No entendimento de Freire (2003), a educação projeta-se, também, com uma dimensão política que pretende, ao prover o indivíduo de condições intelectuais autônomas, despertar seu reconhecimento como sujeito social ativo. Através da observação e das narrativas, percebeu-se que as práticas democráticas experienciadas nos trabalhos em grupo assentam-se em dois pilares: o reconhecimento dos direitos e deveres de cidadania e o aprendizado dos princípios fundamentais que regem os procedimentos jurídicos. A identidade de sujeito de direitos, definida por Ernesto como "zelador de direitos", explicita a importância que os jovens conferem ao conhecimento de seus direitos, integrando esta perspectiva de forma natural no seu discurso.

Esta identidade repercute na reivindicação consciente pela efetivação desses direitos e é estruturadora de um modo de agir consonante. Como expressa Benedito, os jovens passam a "compreender sua liberdade como" uma ética de "responsabilidade com o coletivo". Nesse sentido, a vivência na organização arregimenta o elo entre a transformação pessoal e a transformação social, mediante a percepção de que sua conquista pessoal subjaz a luta política cotidiana e institucional.

Com o envolvimento com o social, com a coletividade, você transforma sua vida em uma militância integral, em tempo integral, porque você faz isso na sua casa, no trabalho, com seus amigos. Mas é de a gente estar dialogando, provocando para estimular, contribuir com algumas mudanças de posturas. (Marcel)

As discussões e os debates promovidos pela ONG oferecem pontos de referência para a constituição da identidade pessoal e coletiva dos jovens. Na dinâmica participativa, os valores evocados de forma natural, interativa, geram uma atitude filosófica diante de temas como a orientação sexual, relações entre os gêneros e a violência doméstica. Tal como discorre Marcel: 
No momento que eu reflito uma questão, tipo violência doméstica, e eu consigo ver de forma significativa aquilo para minha pessoa, minha construção enquanto individuo, enquanto sujeito, isso se reflete diretamente na minha relação com minha mulher, na relação com minha filha, com minha mãe e com as outras mulheres do espaço onde eu trabalho.

A dialogicidade sistematicamente engendrada, enquanto forma de integrar-se e de promover espaço à voz do outro, oportuniza aos jovens redefinir a si mesmos e a sua condição humana, antes vislumbrada em aspectos superficiais. Os conteúdos trabalhados pela organização são basilares ao seu desenvolvimento, envolvendo temas como as mudanças corporais na adolescência, a descoberta da sexualidade e as práticas sexuais. Entretanto, obter informações para a saúde constitui apenas o ponto de partida para a aprendizagem. Nas palavras de Ernesto, "a informação é importante sim; mas, desde quando o indivíduo saiba como é que ele transformará essa informação em ação".

De fato, o autocuidado é uma relação de atenção e zelo que o indivíduo estabelece consigo mesmo. Encerra uma noção subjetiva forjada na compreensão fenomenológica, que comporta uma nova percepção dos determinantes socioculturais da saúde. Para entender como funciona este processo na organização, recorre-se à narrativa do jovem supracitado, quando ele explica como a informação transfigura-se em objeto de uma análise crítica, por jovens e educadores:

Saber qual o significado que a informação tem para a vida é grandeza do processo da construção do conhecimento. [...] Não é dizer: você tem que usar camisinha porque é importante pra sua vida. [...] $\varepsilon$ vocêter a possibilidade de conhecer, com o educador questionando: "O que você acha disso?". Normalmente o que vem é o que o senso comum traz. "Mas você já pensou por esse olhar?", e depois ele faz provocações: " $E$ de que forma isso se encaixa na sua vida? Como você se deu com o preservativo? Qual a importância do uso?" [...]. Você está fazendo o outro pensar sobre aquilo, perceber que é importante [...].

Enquanto componente motivador da ação, temse que é o sentido atribuído o que impulsiona os jovens a assumir uma postura capaz de se sobrepor a desejos e prazeres momentâneos. Através da problematização, eles se apossam do conhecimento, posicionando-se sobre o que a informação representa para eles e como se encaixa em suas vidas. Nesse movimento a informação não se perde, nem tampouco resta inócua, passa, em verdade, a estar associada a uma atitude de bem viver.

A decisão por assumir uma postura em prol da saúde é resultante do conhecimento sobre seu corpo. Os jovens referem-se ao corpo como parte de si e referencial de bem-estar. 0 desenvolvimento de um valor positivo para o corpo advém da percepção de "que é importante, é fundamental para as escolhas que se faz da vida", como afirma Liliana.

\section{Aprendizagem cooperativa: o relevo do grupo e o novo papel do educador}

A aprendizagem cooperativa é definida como o conjunto de processos nos quais os educandos se focam na ideia do trabalho coletivo, a fim de alcançar uma determinada meta ou objetivo, sob a orientação de um educador centralizado nestes processos (Bessa e Fontaine, 2002). Baseada na interação social, essa metodologia de ensino permite a liberdade de posicionamento e a discussão, estimulando habilidades sociais e a construção de sentidos (Aguado, 2000).

Na estrutura organizacional cooperativa, o educador passa a ser o "mediador na construção de conhecimento" (Aguado, 200o, p. 47). Em que pese seu "poder do especialista”, ele não é a figura central na produção do saber, os parceiros de grupo são vistos como recurso de aprendizagem em primeira instância.

Foi possível perceber que, para além da necessidade de afiliação, há um forte componente de interdependência entre os jovens do grupo de trabalho, que promove o fortalecimento das relações interpessoais e a avaliação positiva do processo educativo (Johnson e Johnson, 1999). No caso da ONG, a convivência com os pares adiciona uma perspectiva lúdica ao ato pedagógico, conferindo-lhe a leveza que se traduz na fala de Liliana: "porque a descontração ajuda ao trabalho fluir, e a gente se sente mais confiante de falar com outros jovens". Contrasta com a relação vertical estabelecida no modelo tradicional de transmissão do saber, que segundo os entrevistados, inibe a sua participação, mesmo que seja para tirar dúvidas. 
De acordo com Slavin (1995), o protagonismo dos educandos na construção do conhecimento assentase na responsabilidade de aprender. Verificou-se que esta responsabilidade, então reconhecida, constitui uma dinâmica que envolve discussão, argumentação e negociação enquanto etapas essenciais, que vão preenchendo lacunas de entendimento uns dos outros. Em consonância, os jovens entrevistados destacam a interajuda e a partilha de experiências e visões de mundo como elementos fundamentais no esclarecimento e na compreensão dos conceitos em estudo. Seus relatos demonstram a valorização das informações e ideias trazidas pelos colegas, consideradas um fator decisivo na aceitação do conteúdo trabalhado. Esta integração de saberes relaciona-se tanto a corresponsabilidade na educação, com a qualidade do discurso partilhado, quanto à forma como os significados sociais e culturais são interativamente produzidos.

Observou-se que em pequenos grupos de trabalho cooperativo, os jovens são chamados a expor suas ideias. As indagações potencializam a (re) construção de entendimentos, atuando como meio para o desenvolvimento da capacidade de agir sobre a informação. A intersubjetividade no processo de apropriação do conhecimento permite que cada jovem se descentralize, fazendo uma análise que ascende ao diálogo entre as percepções e os pontos de vistas distintos do seu. Os vários prismas convergem em uma compreensão mais complexa do objeto analisado, possibilitando uma transformação mais significativa do que se está a aprender.

Segundo Freitas e Freitas (2004), ao formular e verbalizar um discurso, os educandos constroem pensamentos mais estruturados e organizados. Em concordância, os entrevistados consideram salutar a possibilidade de descrever suas ideias e explicar suas razões. Para eles, constituir uma visão sobre "ser saudável" envolve construir, refletir e integrar conceitos e procedimentos de saúde. 0 movimento educativo da ONG configura-se no manuseio desses conceitos. Como expressa Sofia, "o encanto dessas descobertas" impulsiona ações de cuidado com o corpo, "porque agora se sabe o que é esse corpo [...] entendendo sua importância para o nosso bem-estar".

Para que os jovens sejam efetivamente sujeitos na produção do conhecimento, o educador assume um novo papel no processo educativo, qual seja o de observador (Aguado, 200o). Na organização estudada, ele estabelece canais de comunicação com os grupos de trabalho juvenis, mediante o feedback permanente e em tempo útil avalia o desempenho individual e do grupo. De modo a ajudá-los a reconhecer percepções equivocadas ou preconcebidas sobre doenças ou aspectos sobre seu corpo e sua sexualidade, oportunizando a afirmação de alguns comportamentos e modificação de outros. Esse feedback foi importante, por exemplo, para Marcel compreender que "a masturbação é uma forma de expressão sexual, uma forma de eu conhecer meu corpo e aprender a lidar como meu prazer" ou João reconhecer a homossexualidade como "uma orientação sexual, não um risco de contrair doenças, porque os cuidados que se tem que ter são os mesmos".

Em suas narrativas, os jovens ressaltam a importância do vínculo afetivo com o educador. 0 trato atencioso e a disposição para conversar são citados como um diferencial desse ambiente educativo. João sintetiza essa atitude de abertura: "[...] é de ter tempo e de querer atender questionamentos dos jovens. Ter a vontade e a satisfação de explicar, de compartilhar o conhecimento. [...] essa disponibilidade de estar junto é uma atitude do educador que reverbera nos ouvidos, na cabeça”.

Os jovens estabelecem um contraste entre a postura dos educadores e a falta de diálogo ou inabilidade de pais e professores para discutir temas de interesse, relacionados a conflitos psicológicos e identitários provocados pela condição juvenil. Neste ponto, em conotação negativa, eles se referem à "rua" e aos "amigos" como únicas alternativas disponíveis para sanar dúvidas e obter conhecimentos sobre o uso de preservativos, as várias formas de iniciação sexual e de praticar sexo ou informações sobre o efeito de drogas. A vivência em uma comunidade caracterizada por eles próprios com um ambiente de risco, recrudesce-se em relações, agora, percebidas posteriormente como potencialmente prejudiciais nos planos cognitivo e atitudinal.

Outro elemento destacado na prática metodológica da ONG é a atuação articulada dos educadores. Sob o ideal da integralidade, o planejamento dos conteúdos de cada área temática busca estabelecer uma convergência com a totalidade dos trabalhos desen- 
volvidos. Destarte, como defendem Bessa e Fontaine (2002), o trabalho colaborativo entre educadores é um contexto favorável para a experimentação de novas situações didáticas, que maximizem a aprendizagem. Contribui, também, para o acompanhamento sistemático desses jovens através da troca de informações sobre seu desempenho escolar, a relação com a família e a sua evolução no grupo. Conhecer as pessoas envolvidas no processo de aprendizagem é o que possibilita aos educadores transpor o âmbito cognitivo e apoiá-los em seu desenvolvimento social e afetivo, estabelecendo alianças a partir de elos que fortaleçam a assertividade juvenil.

A cooperação que emerge na ONG pode ser entendida, fundamentalmente, como uma prática cultural, um modo de vida edificado na integração e no apoio mútuo (Slavin, 1995). As competências cooperativas adquiridas no grupo têm sido utilizadas no cotidiano dos jovens cidadãos quando agem na reivindicação de direitos e na transformação social a partir do senso de responsabilidade e de solidariedade social.

\section{Educação entre pares: uma motivação para aprender}

A concepção de educação entre pares desenvolve-se na estrutura horizontalizada de relações entre os participantes e na partilha de experiências enquanto elementos-meio para a construção do conhecimento, permitindo, simultaneamente, promover o desenvolvimento do outro e de si mesmo (Shiner, 1999; Alcock e col., 2009).

$\mathrm{O}$ ato de compartilhar é fundamental para o estabelecimento de uma relação baseada na escuta e no diálogo construtivista entre o saber técnicocientífico e o saber prático (Ayres e col., 2003). Na prática metodológica da $\mathrm{ONG}$, a educação entre pares cumpre a função de "dinamizar" o conhecimento entre os jovens. Esta abordagem bifurca-se na figura do monitor e na figura do agente social. 0 primeiro é responsável por mediar a discussão e a troca de saberes nos grupos, contribuindo com a identificação dos pares com o tema em pauta, ao passo que o jovem como líder ativista atua na sensibilização e mobilização comunitária para a luta pela efetivação dos direitos sociais.

Através da proposta de trabalho em grupo, cada jovem assume a corresponsabilidade na aprendi- zagem dos colegas, desempenhando papéis diferenciados na resolução das atividades. Verificou-se que a participação ativa abarca todo o processo de “construção continuada" do conhecimento desde o planejamento do currículo anual até a avaliação das atividades, diferenciando-se, nesse sentido, da estratégia de peers-led information. Esta estratégia caracteriza-se pela mera reprodução da mensagem técnico-científica adaptada e em linguagem adequada ao estilo de vida, grupo social e idade do públicoalvo (Turner e Shepherd, 1999).

Segundo Braungart e Braungart (1996), os jovens têm cultura própria, distinta da cultura dominante, referenciada por símbolos, crenças e comportamentos que expressam a singularidade da condição juvenil. Expressando concordância, as narrativas dos jovens explicitam que o senso de pertencimento torna-se um fator de "sedução" para o seu ingresso na ONG. A frase "é jovem falando para jovem" foi citada por todos os entrevistados quando lhes foi perguntado o que lhes motivou a participar.

[...] eram jovens falando para jovens da necessidade do cuidado com o corpo, da prevenção do HIV/ AIDS, da participação social, em como a gente podia interferir nos problemas que eram nossos e que geralmente a gente via como se não fossem, como se fosse uma coisa à parte. Quando eu vi, eu falei: nossa, eu também quero participar, expressar o que eu estou sentindo agora através dessa estratégia. (Sofia)

A convivência na organização apresenta-se como forma alternativa de "estar juntos", para além dos problemas experienciados na escola e na comunidade. Os recursos lúdicos mostram-se essenciais para a mobilização dos jovens, constituindo um fator de adesão, como um "ponto de partida para começar a tomar gosto pela história”, como profere Elisa.

De fato, as atividades lúdicas propiciam a vivência plena do aqui-agora, integrando a ação, o pensamento e o sentimento, de modo a construir uma dimensão afetiva que impulsiona a sensibilidade e o envolvimento (Luckesi, 2007). Segundo os relatos dos entrevistados, a consciência da importância do que estavam aprendendo não foi imediata ao ingresso na ONG, sendo construída no processo de sociabilidade, na "farra dos encontros, nas brinca- 
deiras e rodas de violão". Ernesto recorda que "eram as pessoas que já estavam adultas que tinham esse comprometimento [...] e apesar desses momentos de lazer [...] eles provocavam a discussão sobre a importância de tá ali, de poder falar o que você pensa, fazendo com que eu fosse percebendo isso, conforme fui amadurecendo".

Verificou-se que, por meio da arte, a organização conecta os jovens com o âmago de suas crenças, sonhos, aspirações, medos, ansiedades - sentimentos estreitamente relacionados à construção da identidade. A linguagem cênica facilita a abertura dos jovens para falar sobre temas difíceis que lhes afetam intimamente.

Expressar sua condição juvenil construída em meio às dificuldades relacionadas às desigualdades sociais, através da leveza do riso, da alegria e da emoção, move-os para além do imediato, da aridez circunstancial das áreas pobres nas quais residem. Transpondo suas dores, eles aprendem a redimensioná-las em uma trajetória de vida que pode ser transformada por sua própria ação.

O cotidiano da criação das peças trabalha no plano da consciência, com temas que representam os jovens em sua diversidade de dilemas identitários. Ancestralidade, preconceito racial, vulnerabilidade a DST/AIDS, gravidez na adolescência e direitos reprodutivos são alguns dos temas transversais que constituem a matriz discursiva com a qual eles organizam sua identidade individual e coletiva, diante das expectativas sociais e culturais simbolizadas na representação social negativa de imaturidade e irresponsabilidade juvenil.

Segundo Geertz (1989), a arte exprime as representações que o homem constrói a partir de sua leitura do mundo, na perspectiva de conhecer e intervir sobre a realidade. Através das narrativas, foi possível perceber como esse espaço de discussão possibilita a cada jovem reconstituir sua história de vida nas formas de contar e pensar trabalhadas. Esta condição criativa, portanto, uma vez autorizada e bem acolhida, reverbera no reconhecimento do seu papel na melhoria das condições de vida de sua comunidade.

Essa transformação atitudinal ocorre pelo despertar dos sentidos que passam a atuar de forma integrada. Trata-se de compreender e sentir o que antes era ignorado ou lhes gerava indiferença. A arte, em sua base estética, propõe o reencontro do ser humano com as suas dimensões fluídas, com o mundo que o cerca e suas experiências nele. 0 mundo vivido é o sujeito em associação, como coloca Merleau-Ponty (2004, p. 33): “eu não o vejo [o espaço] segundo seu envoltório exterior, vivo-o por dentro, estou englobado nele. Pensando bem, o mundo está ao redor de mim, não diante de mim".

Ao estar com o mundo, o jovem deixa de concebêlo como um externo e passa a fazer parte dele, com todos os seus fenômenos, desdobramentos e possibilidades vivenciados como um continuun de si. A dimensão sensível passa a integrar sua consciência de mundo, tal como pontua Elisa: "o teatro abriu meus horizontes, me abriu pro mundo [...] hoje eu vejo um mendigo dormindo no chão, eu penso na dignidade dele, eu vejo que a gente pode interferir porque esse problema é nosso e eu não via como se fosse, não significava nada”.

O envolvimento social dos jovens decorre do objetivo de "provocar atitudes transformadoras de si e da sociedade em que vivem" (CRIA, 2010). Nesse intuito, a ONG desenvolveu a noção de "dinamizador cultural" que comporta o senso de compromisso com o outro, através da responsabilidade de compartilhar o conhecimento adquirido na sua comunidade.

As apresentações de espetáculos e a realização de Feiras Culturais integram um processo de formação para a cidadania que visa construir laços sociais a partir da conscientização social dos jovens e fortalecer a participação da comunidade nos espaços de deliberações públicas. Segundo a coordenadora da área de saúde do CRIA, as várias expressões artísticas utilizadas são "um convite à comunidade para pensar nos seus direitos [...] dando visibilidade às formas de violação desses direitos, para, em conjunto, pensar estratégias coletivas de ação".

Organizados em grupos de trabalho, os jovens atuam na articulação de ações coletivas com a escola pública, o centro de saúde e a associação de moradores. Eles realizam um trabalho de pesquisa e observação problematizadora do cotidiano que fundamenta a elaboração de peças teatrais, vídeos e livretos sobre a história, a identidade e a situação social do bairro.

Esta nova forma de vivenciar o espaço redi- 
mensiona a relação dos jovens com a comunidade. Como resultado desse processo, muitos deles vêm se transformando em referência da sua comunidade. Eles percebem que há ações de mudança social ao seu alcance. Como pondera Elisa, "no trabalho do dia a dia também se pode tornar uma situação melhor [...] mesmo que não seja o ideal já é um salto de qualidade". Nesse intuito, os jovens têm desenvolvido diversas atividades, com destaque para a organização de grupos de advocacy com outros jovens da vizinhança; a atuação como educadores fomentando a leitura, ministrando palestras e cursos sobre direitos humanos, cultura da paz e participação social em associações de moradores; a formulação e implantação de projetos sociais ou o engajamento no grêmio escolar.

As narrativas revelam o caráter transformador da participação na ONG com o desenvolvimento do propósito de vida, do sentimento de valor e de competência pessoal e da capacidade de ação. Este percurso pedagógico recursa os jovens para assumir o controle da vida, configurando um conjunto de ferramentas pessoais e sociais para seu empowerment:

O diferencial daqui é que é uma educação para além de ela valorizar o que o indivíduo traz com ele de bagagem, de experiência [...], ela transforma o jovem em sujeito [...], eu tive possibilidades de reflexão, para questionar, ser critico frente a minha realidade. [...] penso que construir um sujeito é fazer com que a pessoa tenha uma postura ativa frente aos problemas que ela enfrenta, de mudar a vida para melhor [...] não esperar sempre que alguém faça alguma coisa por ela. Por isso eu acredito que essa educação prepare o sujeito pra vida. (Marcel)

\section{Conjugando a integralidade: em busca de uma perspectiva pluridimensional}

A Educação em Saúde, enquanto parte integrante no processo educacional, configura-se como um espaço de convivência e ação para esses jovens. A organização de grupos em sistemas horizontais de participação propicia aprendizados que favorecem o desenvolvimento do educando, como alguém que pensa, sente e age de forma coerente e integrada.

A prática pedagógica da ONG estudada apresenta importantes pontos de convergência com o modelo de educação pluridimensional proposto pela UNES-
CO (Organização das Nações Unidas para Educação, Ciência e Cultura), em prol da renovação pedagógica para o século XXI. Fundamentalmente, conforma uma concepção ampliada de educação que explora as potencialidades e talentos que "constituem tesouros escondidos no interior de cada ser humano" (Delors, 2004, p. 20). Esta perspectiva sobreleva o papel político da educação enquanto formação para a vida, mediante a promoção de aprendizagens que recursem a pessoa para tomar consciência de si própria e do meio envolvente. Nesse sentido, "a educação é, antes de mais nada, uma viagem interior, cujas etapas correspondem às da maturação contínua da personalidade" (Delors, 2004, p. 101).

Uma educação pluridimensional organiza-se em torno de quatro aprendizagens fundamentais, entendidas como pilares do conhecimento. 0 primeiro pilar refere-se ao processo de aprender a conhecer, isto é, a aquisição dos instrumentos da compreensão. $\mathrm{O}$ aumento dos saberes possibilita compreender melhor o ambiente sob os seus diversos aspectos, estimula o sentido crítico e permite desenvolver a autonomia mediante a capacidade de discernir. 0 segundo pilar, especificado como aprender a fazer, compreende a aquisição de capacidades que permitam ao indivíduo intervir em seu contexto, tais como comunicar-se, trabalhar com os outros, gerir e resolver conflitos. 0 terceiro, aprender a viver juntos, envolve compreender o outro e a percepção das interdependências na participação em projetos comuns, estimulando a cooperação e o respeito pelos valores do pluralismo. Descobrir o outro em suas diferenças e similitudes é condição sine qua non para o autoconhecimento, para uma visão ajustada da alteridade e o desenvolvimento de uma atitude de empatia. Implica, dessa forma, na definição de comportamentos sociais pelos indivíduos ao longo da vida. O último pilar, aprender a ser, é a via essencial que integra as três precedentes. Corresponde ao desenvolvimento das potencialidades humanas para a realização das pessoas em sua totalidade: espírito e corpo, inteligência, sensibilidade, capacidade de autonomia, de discernimento e de responsabilidade pessoal (Delors, 2004; Costa, 2008).

A concepção de educação em saúde apresentada parte de um enfoque ontológico que contempla, além de uma sólida formação conceitual, o desen- 
volvimento de habilidades sociais como a criatividade, a criticidade, a cooperação, a comunicação, a responsabilidade e uma visão de mundo ampliada. Tais habilidades são mediadoras da integração social, provendo aos jovens referenciais para refletir, questionar e posicionar-se de forma mais autônoma e participativa diante de si mesmo e da sociedade.

Trata-se de promover o empowerment juvenil, em uma rede de relações de interconhecimento e de inter-reconhecimento, cujo caráter vinculante não se restringe ao grupo e à instituição, mas, sobretudo, relaciona-se à incorporação de valores do bem comum. A mudança no papel do educando no processo educativo objetiva-se no estímulo à iniciativa na construção dos projetos a serem desenvolvidos e na vivência de possibilidades de escolha e de responsabilidade pessoal. Nessa direção, os recursos oferecidos no processo educativo preparam os jovens para melhor organizar e conduzir sua vida pessoal e coletiva.

A possibilidade de articular a sua aprendizagem, de receber feedbacks dos pares e educadores e de partilhar informações e conhecimentos demonstra ser decisiva no desempenho de papéis sociais e no desenvolvimento de competências para a agência social. Ademais, compreende acionar os meios intelectuais de cada educando para que ele seja capaz de assumir o uso de suas potencialidades físicas, intelectuais e morais para prosseguir na própria formação ao longo da vida.

O modelo de educação em saúde apresentado transversaliza o processo de formação humana ao mover-se na ampliação de horizontes com a construção de um ponto de vista e de percepções sobre conceitos elementares para a manutenção da saúde. Articula-se com a constituição da identidade, do autoconhecimento e de novas formas de atuar em sociedade.

Educar em saúde, neste sentido, é educar para a vida e requer o preparo eficiente dos educandos para que desenvolvam capacidade de análise, de discernimento e de decisão. Em um processo pedagógico que tem como cerne a construção de sentidos enquanto subsídio ao entendimento pessoal do que seja saúde e do significado de ser saudável. Essa autonomia inicia-se com a competência de conduzir o próprio corpo para uma relação saudável consigo mesmo e com o mundo. 0 processo reverbera em escolhas sobre a higiene, alimentação, relação com o meio ambiente e de fortalecimento dos vínculos sociais, e em relação ao uso e ao cuidado do corpo.

A articulação de métodos aqui exposta demonstra que a educação em saúde pode contribuir para o desenvolvimento integral da pessoa, oferecendo um espaço para a formação pessoal e social dos indivíduos. Trata-se de uma dinâmica educacional capaz de auxiliar na aquisição de capacidades físicas e espirituais, preparando-os para a participação ativa e transformadora nas várias esferas da vida, enquanto sujeitos que se reconhecem com este atributo.

\section{Referências}

AGUADO, M. J. Educação intercultural e aprendizagem cooperativa. Porto: Porto Editora, 2000.

ALCOCK, G. et al. Community-based health programmes: role perceptions and experiences of female peer facilitators in Mumbai's urban slums. Health Education Research, Oxford, v. 24, n. 6, p. 957-966, 2009.

ALVES, P. C.; RABELO, M. C. (Orgs.). Antropologia da saúde: traçando identidades e explorando fronteiras. Rio de Janeiro: Relume-Dumará, 1998.

AYRES, J. R. C. M. Sujeito, intersubjetividade e práticas de saúde. Revista Ciência \& Saúde Coletiva, Rio de Janeiro, v. 6, n. 1, p. 63-72, 2001.

AYRES, J. R. C. M. et al. Adolescência e AIDS: avaliação de uma experiência de educação preventiva entre pares. Interface - Comunicação, Saúde, Educação, Botucatu, v. 7, n. 12, p.124-138, 2003.

BESERRA, E.; ARAÚJO, M. F.; BARROSO, M. G. Promoção da saúde em doenças transmissíveis: uma investigação entre adolescentes. Acta Paulista de Enfermagem, São Paulo, v. 19, n. 4, p. 402-407, out./ dez. 2006.

BESSA, N.; FONTAINE, A. Cooperar para aprender: uma introdução à aprendizagem cooperativa.

Porto: ASA, 2002. 
BRAUNGART, R. G.; BRAUNGART, M. M.

Cultura da juventude. In: OUTHWWAITE, W.; BOTTOMORE, T. Dicionário do pensamento social do século XX. Rio de Janeiro: Jorge Zahar, 1996. p. 167-168.

CANDEIAS, N. M. F. Conceitos de educação e de promoção em saúde: mudanças individuais e mudanças organizacionais. Revista de Saúde Pública, São Paulo, v. 31, n. 2, p. 209-213, abr. 1997.

CARVALHO, M. A.; ACIOLI, S.; STOTZ, E. N. O processo de construção compartilhada do conhecimento: uma experiência de investigação do ponto de vista popular. In: VASCONCELOS, E. M. (Org.). A saúde nas palavras e nos gestos: reflexões da rede educação popular e saúde. São Paulo: Hucitec, 2001. p. 101-144.

COSTA, A. C. G. Educação: uma perspectiva para o século XXI. São Paulo: Canção Nova, 2008.

CRIA - Centro de Referência Integral de Adolescentes. O CRIA. 2010. Disponível em: http:// blogdocria.blogspot.com/p/sobre-o-cria.html.

Acesso em: 10 jun. 2011.

CRIA - Centro de Referência Integral de Adolescentes. O encanto poético do CRIA e a vez do Iyá de Erê. 2011. Disponível em: http://blogdocria. blogspot.com/2011/o8/o-encanto-poetico-do-cria-evez-do-iya.html. Acesso em: 10 jun. 2011.

DELORS, J. Educação: um tesouro a descobrir.

Relatório para UNESCO da Comissão Internacional sobre Educação para o século XXI. São Paulo: Cortez; Brasília: MEC, UNESCO, 2004.

FERRAZ, F. el at. Cuidar-educando em enfermagem: passaporte para o aprender/ educar/cuidar em saúde. Revista Brasileira de Enfermagem, Brasília, v. 58, n. 5, set./out. 2005.

FIORIN, J. L. Elementos de análise do discurso. 13 ed. São Paulo: Contexto, 2005.

FREIRE, P. Pedagogia do oprimido. 48 ed. Rio de Janeiro: Paz e Terra, 2005.

FREIRE, P. Pedagogia da autonomia: saberes necessários à prática educativa. 37 ed. São Paulo: Paz e Terra, 2003.
FREIRE, P. Extensão ou Comunicação? 13 ed. Rio de Janeiro: Paz e Terra, 2006.

FREITAS, M.; FREITAS, C. Aprendizagem cooperativa. Lisboa: Edições ASA, 2004.

GAZZINELLI, M. F. et al. Educação em saúde: conhecimentos, representações sociais e experiências da doença. Cadernos de Saúde Pública, Rio de Janeiro, v. 21, n. 1, p. 200-206, jan./ fev. 2005 .

GEERTZ, C. A interpretação das culturas. Rio de Janeiro: LTC, 1989.

GOODMAN, K. S. Introdução à linguagem integral. Porto Alegre: Artes Médicas, 1997.

JOHNSON, D. W.; JOHNSON, R. Learning together and alone: cooperative, competitive, and individualistic learning. Boston: Allyn and Bacon, 1999.

LIMA-COSTA, M. F. et al. Um estudo epidemiológico da efetividade de um programa educativo para o controle da esquistossomose em Minas Gerais. Revista Brasileira de Epidemiologia, São Paulo, v. 5, n. 1, p. 116-128, abr. 2002.

LOPES, R. E.; MALFITANO, A. P. Ação social e intersetorialidade: relato de uma experiência na interface entre saúde, educação e cultura. Interface - Comunicação, Saúde, Educação, Botucatu, v. 10, n. 20, p. 505-515, jul./dez. 2006.

LUCKESI, C. Ludicidade e desenvolvimento humano. In: D’ÁVILA, C. M. (Org.). Educação e ludicidade: ensaios 4. Salvador: Universidade Federal da Bahia, Faculdade de Educação, Gepel, 2007. p. 11-19.

MAGDALENA, B. C.; COSTA, I. E. Internet em sala de aula: com a palavra, os professores. Porto Alegre: Artmed, 2003.

MERLEAU-PONTY, M. O olho e o espírito. São Paulo: Cosac Naify, 2004.

MINAYO, M. C. O desafio do conhecimento: pesquisa qualitativa em saúde. São Paulo: Hucitec; Rio de Janeiro: ABRASCO, 1996. 
OLIVEIRA, D. L. A 'nova' saúde pública e a promoção da saúde via educação: entre a tradição e a inovação. Revista Latino-Americana de Enfermagem, Ribeirão Preto, v. 13, n. 3, mai./ jun. 2005 .

RICE, M.; CANDEIAS, N. M. F. Padrões mínimos da prática da educação em saúde: um projeto pioneiro. Revista de Saúde Pública, São Paulo, v. 23, n. 4, p. 347-351, 1989.

RODMELL, S.; WATT, A. Conventional health education: problems and possibilities. In: . (Eds.). The politics of health education: raising the issues. London: Routledge \& Kegan Paul, 1986. p. 1-16.

SHINER, M. Defining peer education. Journal of Adolescence, Banbury, v. 22, n. 4, p. 555-566, 1999.

SLAVIN, R. E. Cooperative learning: theory, research and practice. Boston: Allyn \& Bacon, 1995 .
SMEKE, E. L.; OLIVEIRA, N. L. Educação em saúde e concepções de sujeito. In: VASCONCELOS, E. M. (Org.). A saúde nas palavras e nos gestos: reflexões da rede educação popular e saúde. São Paulo: Hucitec, 2001. p. 115-136.

TURNER, G.; SHEPHERD, J. A method in search of a theory: peer education and health promotion. Health Education Research, Oxford, v. 14, n. 2, p. 235-247, 1999.

VASCONCELOS, E. M. Redefinindo as práticas de saúde a partir da educação popular nos serviços de saúde. In: VASCONCELOS, E. M. (Org.) A saúde nas palavras e nos gestos: reflexões da rede de educação popular e saúde. São Paulo: HUCITEC, 2001. p. 11-19.

VYGOTSKY, L. S. Pensamento e linguagem. São Paulo: Martins Fontes, 2008.

VYGOTSKY, L. S. A formação social da mente. São Paulo: Martins Fontes, 2007. 